\title{
O talijanskom futurizmu u Rijeci 1919. godine
}

Aвstract: Lukežić Irvin, O talijanskom futurizmu u Rijeci 1919. godine (About Italian Futurism in Rijeka on 1919). "Poznańskie Studia Slawistyczne" 18. Poznań 2020. Publishing House of the Poznań Society for the Advancement of the Arts and Sciences, Adam Mickiewicz University, pp. 225-233. ISSN 2084-3011.

The article discusses the short-lived emergence of Italian futurism in Rijeka, just after the end of World War I, in the context of the political adventure of Gabrielle D'Annunzio, who, with the help of his supporters, an ardite, tried to annex the city to the Kingdom of Italy. At that moment, the avant-garde spirit of Italian futurism could manifest itself here in all its main features: activism, antagonism, nizilism and agonism. In addition to the founder of Italian futurism, Filippo Tommas Marinetti, Mario Carli, Guido Keller and Giovanni Comisso stayed and worked in Rijeka during 1919. The article seeks to describe their actions on the basis of newspaper reports in the Rijeka daily La Vedetta d'Italia.

KeYwords: Italian; literature; avangardism; futurism; D’Annunzio; Rijeka

\section{Uvod}

Okupljali su se spontano u sjeni stoljetne murve, na maloj piazzetti riječkog Staroga grada. Maleni trijem, gdje bi se održavale njihove skupštine, bijaše mjestom stvaranja novoga intelektualnog projekta, avangardnog i utopijskog podjednako. Govorili su svi, bez razlike kojoj misaonoj struji pripadali. Na sastanke bi ljubazno pozivali i svoje idejne protivnike tako da su iz sudara različitih stremljenja, iz sukoba mišljenja prskale veleumne iskre. Djelovali su i na ulicama, gdje su ih ponekad dočekivali s porugom. Imali su običaj penjati se na kavanske stolove i uzdignutim slikama slaviti Italiju i D’Annunzija. Hodali su svijetom poput mjesečara, marširali u ,bojovnim zdrugovima“ $\mathrm{i}$ arditskim odorama, oboružani bodežima i granatama, veličali kult dinamizma i estetiku strojeva, diveći se urlanju 
automobila, vlakova i zrakoplova, ,ljepoti brzine“. Imponirala im je agresivna akcija, grubost i brutalnost, oduševljavahu se sportom i opasnim podvizima, neprestano provocirajući i ujedno pozirajući pred zbunjenim općinstvom. Ime im bijaše znakovito: futuristi.

Pojava talijanskoga futurizma na obalama Rječine u okvirima književnih i političkih previranja danuncijanskoga razdoblja, prije točno stotinu godina, nije se dogodila slučajno i danas predstavlja neobičnu zanimljivu epizodu unutar burne riječke povijesti. Postojale su za to neke značajne pretpostavke.

\section{Povijesne pretpostavke}

Ovaj grad bio je stekao autonomiju još potkraj šesnaestoga stoljeća, 1719. proglašen je slobodnom carskom i kraljevskom lukom, a 1776. zajedno s Hrvatskim primorjem postaje dijelom takozvanoga Ugarskoga primorja, tako da u njemu vlast obnašaju mađarski guverneri. Godine 1822. Rijeka je nakon francuske i austrijske uprave uključena u civilnu Hrvatsku, ali opet je imala na čelu mađarske guvernere. Godine 1848. većina njezinih građana podržavala je mađarsku revoluciju, na što je zaposjedaju postrojbe bana Jelačića, koji postaje njezinim prvim hrvatskim guvernerom. Nakon Austro-ugarske nagodbe (1867.) uslijedila je Hrvatsko-ugarska nagodba (1868.) i takozvana Riječka krpica. U hrvatskoj historiografiji i pravu to je naziv za umetak kojim je na bečkom dvoru promijenjen izvorni članak 66. Hrvatsko-ugarske nagodbe, na temelju kojega je Rijeka sa svojim kotarom proglašena zasebnim državnopravnim tijelom te faktično prepuštena Ugarskoj. Uslijedilo je doba provizorija u kojem vlast ponovno preuzimaju mađarski guverneri, što će potrajati sve do sloma Austro-Ugarske Monarhije.

Godine 1919. Rijeku su okupirale D’Annunzijeve trupe, koje će ovdje ostati punih šesnaest mjeseci. Kaos u kojem se nalazilo tadašnje riječko društvo pružao je idealnu situaciju za praktičnu primjenu novih avangardnih ideja što su strujale s Apeninskoga poluotoka. Stari se svijet nalazio u rasulu, novi svijet još nije bio uspostavljen. Sve su opcije bile otvorene i moguće. Grad bijaše gotovo savršen poligon za eksperimentiranje i demonstriranje ,sadašnjosti podčinjene budućnosti““. 
Avangradni duh talijanskoga futurizma mogao se ovdje manifestirati u svim svojim glavnim značajkama: aktivizmu, antagonizmu, nihilizmu i agonizmu. Rijeka se u futurističkim maštarijama doimala poput obećanoga grada budućnosti. Imponirao je taj ugođaj prividnoga gradskog antipassatisma. Pogled unatrag više nije bio moguć. Otvarale su se nove mogućnosti individualnoga i kolektivnoga djelovanja. Kaos je odisao duhom slobodne inicijative, neslućenih mogućnosti.

Što je zapravo željela ta grupa borbenih, bučnih i ekstravagantnih smušenjaka u jednom njima stranom i potpuno nepoznatom gradu? Futuristi djeluju poput lakrdijaša u dehumaniziranom urbanom prostoru poratne Rijeke. Privučeni avanturom, mogućnošću novoga dinamizma i aktivnoga djelovanja oni traže priliku da iskažu svoj aktivizam i intelektualni ekskluzivizam, nedvojbeno uživajući u svojoj ekscentričnosti i avangardističkoj „superiornosti“. Oni zbunjuju i uznemiruju javnost svojim neobičnim ekscesima. Oni su mahom nervozni i nestrpljivi mladi ljudi koji žele promijeniti ustaljene obrasce građanskoga ponašanja. „Dvadeseto stoljeće izgleda da ima samo jednu želju, da što prije stigne do dvadest i prvog“, primjećuje u jednom aforizmu Umberto Saba. Futuristi su u Rijeci uistinu imali dojam da su već stigli u budućnost, da sudjeluju u stvaranju nekoga novog poretka, posve drugačijega od svega dotad viđenoga.

Riječku futirističku epizodu nije moguće promatrati odjelito od danuncijanskoga fenomena. Budući da je talijanski futurizam od samoga početka imao izrazito nacionalistička obilježja, nije neobično su upravo mnogi futuristi kao borci-arditi svesrdno poduprli D'Annunzijev poduhvat „osvajanja“ Rijeke (tzv. Marcia dei Ronchi), prepoznajući i pozdravljajući u njemu revolucionarni čin rušenja staroga birokratskog sustava i građanske konvencije. Tako je bilo i prigodom kasnijeg marša na Rim (1922.), kada je službeno uspostavljen fašistički režim. Talijanski su futuristi zapravo prigrlili fašizam iz ljubavi prema pustolovini ili zbog emotivne privlačnosti koje u sebi sadrže te političke tendencije. Fašizam epigona toga pokreta bio je čist oportunizam. Stavljajući se u službu fašističke ideologije, postajali su apologeti njene ratne i osvajačke politike podjarmljivanja. 


\section{Protagonisti}

Poznato je da se među prvim pobornicima D'Annunzijeva poduhvata u Rijeci već sredinom rujna 1919. pojavljuje Filippo Tommaso Marinetti, karizmatski osnivač talijanskoga futurizma, u pratnji arditskog kapetana Ferruccia Vecchia, inače futurističkoga kipara. Obojica se već istakoše 15. travnja iste godine, kada su predvodili „,bitku“ protiv socijalista, komunista i anarhista na Piazza Mercanti u Milanu, prigodom koje će fašizam prvi puta zabilježiti pobjedu nad svojim ideološkim protivnicima. Zanimljivo da se D'Annunzio nikada nije službeno izjasnio o futurizmu. Futurizam je pak prilikom nastanka imao izrazito antidanuncijevsko obilježje. Jedna od prvih Marinettijevih knjiga naziva se Les Deux s'envont, D'Annunzio reste (Bogovi odlaze, ali D'Annunzio ostaje). D'Annunzio bijaše tipičan dekadentist, spretan asimilator, eklektičar s površnom modernošću, Marinetti je opet zastupao radikalno kritičan stav prema takvoj književnoj praksi. I premda se u vrijeme rata njihovi politički programi podudaraju u mnogim točkama, futuristi i dalje službeno bijahu antidanuncijevci (A. Gramschi).

Unatoč tome Marinetti je u Rijeci pružio punu podršku D'Annunziju, postajući čak i njegovim glorifikatorom. Tako je bilo na arditskoj proslavi 25. rujna 1919. godine. Oduševljenom se mnoštvu prvi obratio D'Annunzio, veličajući borbene zasluge ardita i nazivajući ih paklenim đavolima (i diavoli dell'inferno). Poslije pukovnika Repetta okupljeni su bučnim aklamacijama pozvali Marinettija da im se obrati prigodnim riječima. Marinetti, koji je u ratu sudjelovao kao kapetan tenkovskog bataljona i bio među utemeljiteljima Talijanske arditske udruge, prenio je prvo vođi pozdrave milanskih Fasci di Combattimento kao i Benita Mussolinija, u to vrijeme još urednika lista Popolo d'Italia. Potom se osvrnuo na „veličanstvenu književnu karijeru Duceovu“ (la meravigliosa carriera letteraria del Duce), posebno ističući tragedije La Gloria i Piu che l'Amore, te njegove kasnije ratne zasluge. Potom je naglasio: „Vi ste, Pjesniče, Vašim letom ponad Beča poklonili Talijanima, na najmodrijem od svih nebesa, božansku plavu ešarpu koju zauvijek nosite na svojim prsima“. Marinetti je još govorio o slavnom pjesniku D'Annunziu, ponosu talijanske nacije, kao čovjeku koji se kao dobrovoljac tijekom čitavoga rata isticao borbenošću i smionim letovima, postavši naposlijetku ,genijalni Zapovjednik“ 
riječke ekspedicije. Svoj vatreni govor Marinetti je zaključio konstatacijom da D'Annunzio predstavlja najljepši primjer „najviše od svih rasa, talijanske rase". Publika je njegove riječi popratila bučnim odobravanjem i višekratnim pozdravom Eia, Eia Alala. I sam se Duce ustao i oglasio riječima „Za Marinettija i Vecchia, vrijedne agitatore, milanski pozdrav Eia, Eia Alala!“ Posljednji je govorio arditski kapetan Vecchi, ističući kako je riječka intervenistička akcija bila dogovarana u Marinettijevoj kući u Milanu u prisustnosti Alcestea de Ambrisa (La Vedetta 27, 3. prev. I. L.).

O dvadesetodnevnom boravku Marinettijevom u Rijeci Antonio Spinosa piše:

Marinetti je na Rijeci bio silno popularan. Svakoga dana prije objeda šetao je on po Corso Dante praćen repinom svojih obožavatelja mladića i djevojaka. Vazda je nosio polucilindar i štap. Od vremena do vremena on bi zastao pa, okružen svjetinom znatiželjnika, udario nasred ulice deklamirati svoje ili stihove inih futurističkih pojesnika kako bi slavio rat, ,jedinu higijenu svijeta i jedini odgojni moral“", kako bi veličao „simfoniju šrapnela“ i kako bi odlučno zastupao „sve žestoke športove što se odvijaju na otvorenom, kako što su tjelovježba, trke, boks“, kako bi poticao mladež ,na omalovažavanje svih akademskih diploma i na oslobađanje od stega tradicionalnih obitelji“ [...] Marinetti je iznenađivao gotovo cijelu Rijeku, ne toliko svojim improviziranim deklamacijama na Corso Dante, koliko svojim kazališnim predstavama u kojima se na pozornici nikada ništa ne bi zbilo, nego bi jedan ili dva glumca manje-više odšutili svoje, a gledateljstvo bi naprotiv divlje urlalo. Ono bi poustajalo sa svojih mjesta i popelo se na sjedišta, grdeći na pasja kola takav njima tuđ oblik kazališta u kome, a upravo je to Marinetti htio, glumci šute, dočim publika svojim luđačkim urlicima nesvjesno predstavlja (Fabrio, 1995, 15).

Po svemu sudeći je upravo ta silna popularnost Marinettijeva morala povrijediti D’Annunzijevu pjesničku i lidersku sujetu tako da će on, iskoristivši objede da su ta dvojica futurista širila „pobunjeničku promidžbu“, potpisati dekret o njihovu protjerivanju. Stoga će već 30. rujna Marinetti i Vecchi napustiti Rijeku. Na prvim parlamentarnim izborima u Italiji u studenome iste godine, kada je Fašistička stranka pretrpjela značajan poraz od talijanskih socijalista, Marinetti i Vecchi, zajedno s Mussolinijem, Bolzonom i petnaest ardita, uhićeni su radi remećenja javnoga reda i mira te osuđeni na dvadeset i jedan dan tamnovanja u zatvoru San Vittore.

Nedugo nakon njihova odlaska, početkom listopada iste godine, u Rijeku dolazi istaknuti futurist Mario Carli, također kapetan ardita, književnik i novinar, jedan od autora Manifesta futurističke znanosti (1917.) 
i urednik lista L'Ardito. Tijekom rata bio je ranjavan i odlikovan ordenjem za hrabrost. Zajedno s već spominjanim futurističkim kiparom Ferucciom Vecchijem u Futurističku stranku pripustio je dobrovoljačke jurišne odrede ardita koji postaju Fasci Futuristi, preobrazivši se potom u Mussolinijevu Fašističku stranku, utemeljenu 23. ožujka 1919. u Circolo Industriale e Commerciale na Piazza San Sepolcro u Milanu. Zbog njegove političke djelatnosti Carlija je Nittijeva vlada osudila na tri mjeseca zatvora, odakle uspijeva pobjeći i pronaći privremeno utočište u Rijeci. Okupivši se tada oko Carlija, riječki su futuristi smjesta osnovali svoj Fascio Futurista fiumano. Njega su, osim Carlija, sačinjavali Cesare Cerati, Federico Pinna, Otto Guglielmino, Tino Tesoni, Nino Rasa, Angelo Scambelluri, Italo Binelli, Giuseppe Cavagnetto, Eros Vecchi, Mario Panicali, Giuseppe Zanetti, Achille Achillini, Renato Vigevani, Edilio Guglielmino i drugi. „Djelovanje futurista odvija se u apsolutnoj odanosti riječkoj i talijanskoj stvari, te su oni nestrpljivi da pruže nove dokaze privrženosti svetoj stvari. Uskoro je u Teatru Verdi predviđena jedna futuristička večer na kojoj će Riječani imati priliku upoznati se s temeljnim idejama tog omladinskog pokreta“ (La Vedetta 50, 3. prev. I. L.).

Dugo najavljivana i pomno pripremana futuristička večer „Fantasie Ardite“, koju je priredio Carlijev Teatro Futurista Sinestetico u riječkom općinskom kazalištu 28. listopada 1919., bila je dočekana kao prvorazredna senzacija. Pred riječkom je publikom, naviklom na tradicionalni građanski teatar, prvi put bila odigrana jedna takva avangardna priredba. Svi glumci bijahu pripadnici arditskog Osmog jurišnog odreda. Parter i galerije bijahu dupkom ispunjene radoznalim gledateljstvom, ponajviše veselom, nasmijanom i dobro raspoloženom riječkom mladeži. Markiza Incisa di Cammerana i nekoje riječke gospođe iskoristile su prigodu da arditima podijele darove prikupljene dobrovoljnim prinosima. Prisutnima se prije početka predstave obratio uvodnim kraćim govorom o arditizmu u ratu i miru kapetan Mario Carli:

Mnogi od nas [...], već su se vratili u civilni život. I kroz vrlo kratko vrijeme svi ćemo se vratiti. Dakle, upravo je sada trenutak da započnemo naše djelo širenja arditizma među one koji još nisu upoznali rata i nisu osjetili miris baruta osim možda u kakvu skladištu streljiva, među strašljivce i pacifiste kojima imate zadaću propagirati našu srčanost i našu spremnost za žrtvovanje života. Ako ste radnici, imat ćete poučiti vaše drugove na poslu da nije vrijedan živjeti onaj tko, povrh zakona vlastita želuca, nije kadar 
žrtvovati se za uzvišene ciljeve Domovine i humane pravičnosti. Ako ste namještenici, kažite vašim kolegama, uspavanim u letargičnome ozračju ureda, da valja dići pogled od protokola i usmjeriti ga kroz prozore, prema uvijek novim i različitim nebesima, bez straha pred dosadnim strašilom kakva je odgovornost (La Vedetta 55, 3, prev. I. L.).

Sam futuristički spektakl, koji je repriziran i narednoga dana u općinskom kazalištu, izazvat će prilično kontroverzne reakcije među riječkim općinstvom, nenaviknutom na avangardističke kazališne ekscese. Nesporazumi su vjerojatno nastali radi neprimjerenoga ponašanja nekih osoba iz publike, koje bi urlajući u znak protesta povremeno bacali na pozornicu komade željeza, kamenje i druge slične opasne predmete. Na pozornici se zapravo ništa nije događalo, glumci uglavnom nisu izgovarali nikakav tekst, sve se doimalo nerazumljivo i dosadno. Zazorne su bile i grube verbalne reakcije mnogih posjetitelja. Stoga su takve priredbe vrlo brzo postale odbojne većini kazališne publike, a sam termin „futuristička večer“ postaje sinonimom neprikladnog i neciviliziranog ponašanja. U komentaru prvih futurističkih predstava u Rijeci, koji donosi dnevnik La Vedetta d'Italia, nepotpisani novinski suradnik primjećuje:

Spektakli kakve vidjesmo u našem kazalištu tijekom jučerašnje i prekjučerašnje večeri, završiše epilogom posve različitim od onih koji bijahu uobičajeni u druga vremena, u starim kazalištima stare Italije. Odlučno se protivimo takovim bučnim manifestacijama kakve se odvijaju u suvremenoj Italiji, gdje ima mnogo više slobodna vremena i više ili manje volje za smijeh, više ili manje zabave, budući da one nisu prihvatljive u nas, gdje treba mnogo smirenosti i sabranosti, gdje prije svega valja odbaciti svaku neslogu između građanstva i vojske, između zapovjednika i njihovih podčinjenih, kao i popuštanje sjajne discipline osobne vjere - što dosad bijaše naša najveća vrlina - što bi se pak moglo lako moglo razviti uslijed futurističkih ili antifuturističkih manifestacija kao naravne posljedice jezičnog i tjelesnog nasilja.

Futurizam će zasigurno postati velika i lijepa stvar: ali mi ipak dajemo prednost našoj slozi, pasatističkoj kako neki vele, ali zato sređenoj, jednostavnoj i čovječnoj slozi koja može zadržati na okupu sve duhove koji su u Rijeci uime Italije i za Rijeku.

A futurizam ili antifuturizam nemaju pravo remetiti takvu slogu.

Sinoć su se u kazalištu i izvan njega mogle čuti takve riječi i povici koje nije moguće ponoviti a da se u javnosti ne stvori dojam kako su ovdje izrečeni samo radi buke, i potvrđujući, kao što već bijaše potvrđeno, da je riječki poduhvat nadahnut futurističkom riječju.

Futurizam i antifuturizam pojavljuju se u nas kako bi poduprli sveti cilj: o tome se izjasnio svojevremeno i futuristički prvak F. T. Marinetti u vrijeme svoga boravka u Rijeci, odbacujući svaku manifestaciju koja bi mogla na bilo koji način ugroziti ozbiljnost našeg uređenog i civiliziranog života.

Toliko o tome (La Vedetta 56, 3. prev. I. L.). 
Riječki su futuristi 1919. objavili i svoj manifest pod naslovom $M a$ nifesto degli artisti futuristi qui convenuti per illuminare l'imbecillità dei podagrosi passatisti che sbavano in questa citta (Manifest umjetnika futurista pridošlih ovamo da rasvijetle slaboumnost kostobolnih pasatista koji sline u ovom gradu), tiskan u riječkom tiskarskom zavodu „Minerva“ na sedam nepaginiranih stranica. Početkom 1920. Mario Carli je, zajedno sa Cesarom Ceratijem, također članom Riječkog futurističkog fascija, pokrenuo arditski/legionarski tjedni list La Testa di Ferro (Željezna glava), nazvan tako po D'Annunzijevoj metafori za Riječane, koji potom izlazi i u Milanu. U lipnju iste godine pripadnici arditsko-avangardističkog kulturnog pokreta „Yoga“, koji utemeljuju futuristi Guido Keller i Giovanni Comisso, izdaju zbornik Citta di vita (Grad života) koji uređuje Mino Somenzi. Keller bijaše zrakoplovni poručnik i D’Annunzijev suradnik. Giovanni Comisso, rodom iz Trevisa, također riječki legionar, nakon odlaska iz Rijeke putovao je sjevernom Europom, Afrikom i Dalekim istokom, objavivši veliki broj knjiga memoarskoga i putopisnoga karaktera (Pužar, 1998, 232-238).

\section{Odlazak}

Nakon odlaska D'Annunzija iz Rijeke organizirani riječki futuristički pokret postupno zamire. Na temelju Rapalskoga ugovora (1920.) Rijeka je bila proglašena Slobodnom Državom, ali je Rimskim sporazumom pripala Kraljevini Italiji, pod čijom će vlašću ostati sve do njezine kapitulacije. Učvršćivanje talijanske vlasti i Mussolinijeva režima posve će izmijeniti kulturnu klimu grada u kojoj za futuriste više nije bilo mjesta. Obični ih građani Rijeke u svojoj dobroćudnoj i statičnoj, mirnoj i tradicionalizmu naklonjenoj sredini ionako nikada nisu ozbiljno uzimali. Futurističke provokacije, ulični i kazališni ekscesi, kao i avangardni umjetnički eksperimenti na području javne riječi predstavljali su javnu sablazan koju njihov filistarski duh nije mogao razumjeti ni prihvatiti. 


\section{Literatura}

Fabrio, N. (1995). D’Annunzio, Mussolini, Lenjin, Krleža. „Republika“ 1-2, str. 11-22. Pužar, A. (1998). Pisani tragovi riječkog futurizma. „Riječki filološki dani“ sv. II, str. 232-238.

La Vedetta 27 - Gabriele d'Annunzio festeggiato dagli Arditi. „La Vedetta d'Italia“ br. 27, 26. rujna 1919. Prev. I. L.

La Vedetta 50 - I futuristi a Fiume. „La Vedetta d'Italia“ br. 50, 23. listopada 1919. Prev. I. L.

La Vedetta 55 - Teatro Verdi. „La Vedetta d'Italia“ br. 55, 29. listopada 1919. Prev. I. L.

La Vedetta 56 - Futurismo e Concordia. „La Vedetta d'Italia“ br. 56, 30. listopada 1919. Prev. I. L. 